\title{
PEMBANGUNAN BERKELANJUTAN BERBASIS MORAL: PEMIKIRAN PEMBANGUNAN P.A.A. SOERIA ATMADJA DALAM DI TIOENG MEMEH HOEDJAN
}

\author{
Awaludin Nugraha \\ Departemen Sejarah dan Filologi, Fakultas Ilmu Budaya \\ Universitas Padjadjaran, Bandung-Indonesia
}

Alamat korespondensi: awaludin.nugraha@unpad.ac.id

Diterima/ Received: 27 Juni 2018; Disetujui/ Accepted: 28 Agustus 2018

\begin{abstract}
The development is essentially a constructive effort to make a better life for everyone. Various development theories have been produced to make this happen. In the history of Indonesia, there was a Regent who inherited the developmental thoughts in the next generation. He was Prince Aria Soeria Atmadja or Prince of Mecca, Regent of Sumedang in the period of 1883-1919. He wrote his development ideas in the book "Di Tioeng Memeh Hoedjan". The purpose of this article is to understand the developmental thoughts of Aria Soeria Atmadja. This research used the qualitative method with more emphasize on the hermeneutic approach, especially using hermeneutical circles. The result shows that the developmental thoughts of Aria Soeria Atmadja expressed in Sundanese with figurative language style because of the colonization. His thoughts were a formulation of his experience when he was in a government bureaucratic official. His developmental thoughts were in line with the Sustainable Development theory that developed in the 1980s and emphasized morality as its basis. He also emphasized the importance of community involvement in the development process.
\end{abstract}

Keywords: Morality; Pangeran Mekah; Sustainable Development.

\begin{abstract}
Abstrak
Pembangunan pada dasarnya adalah upaya konstrukstif untuk membuat kehidupan yang lebih baik bagi semua orang. Berbagai teori pembangunan telah diproduksi untuk mewujudkan hal tersebut. Dalam sejarah Indonesia ada seorang Bupati yang mewariskan pemikiran pembangunan pada generasi penerusnya. Ia adalah Pangeran Adipati Aria Soeria Atmadja atau Pangeran Mekah, Bupati Sumedang periode 1883-1919. Ia menuliskan pemikiran pembangunannya dalam buku Di Tioeng Memeh Hoedjan. Tujuan penulisan artikel ini adalah untuk memahami pemikiran pembangunan Pangeran Adipati Aria Soeria Atmadja. Untuk mewujudkan tujuan tersebut digunakan metode penelitian kualitatif dengan pendekatan hermeneutika. Analisis datanya menggunakan lingkaran hermeneutika. Hasilnya menunjukkan bahwa pemikiran pembangunan Pangeran Adipati Aria Soeria Atmadja dikemukakan dalam bahasa Sunda dengan gaya bahasa kiasan karena sedang dalam kondisi penjajahan. Pemikirannya merupakan formulasi dari pengalamannya selama menjabat sebagai pejabat pemerintahan. Pemikirannya selaras dengan teori pembangunan berkelanjutan yang berkembang pada 1980-an dengan penekanan pada moralitas. Ia menekankan arti penting keterlibatan masyarakat dalam proses pembangunannya.
\end{abstract}

Kata Kunci: Moralitas; Pangeran Mekah; Pembangunan Berkelanjutan.

\section{PENDAHULUAN}

Pembukaan Undang-Undang Dasar Negara Republik Indonesia Tahun 1945 mengamanatkan bahwa Pemerintah Negara Indonesia harus melindungi bangsa Indonesia, tanah air Indonesia, memajukan kesejahteraan bangsa Indonesia, mencerdaskan kehidupan bangsa, dan terlibat dalam ketertiban dunia yang berdasarkan kemerdekaan, perdamaian abadi, dan keadilan 
sosial. Amanat tersebut dapat terwujud bila dilakukan proses pembangunan yang terrencana dan berkesinambungan. Pembangunan pada dasarnya adalah upaya konstrukstif untuk membuat kehidupan yang lebih baik bagi semua orang (Peet dan Hartwick, 2015). Hal itu berarti pembangunan merupakan sebuah upaya yang dapat membawa masyarakat mengikuti sebuah proses untuk mencapai kondisi kehidupan yang sebelumnnya dianggap tidak baik, atau kurang baik, menjadi lebih baik. Untuk mewujudkan kondisi kehidupan yang lebih baik itu tidak tunggal. Banyak sudut pandang dan kepentingan, sehingga ukuran dan kriterianya berbeda. Perbedaan sudut pandang itu dimungkinkan karena adanya perbedaan teori pembangunan.

Beberapa ahli telah memberikan sumbangan pemikirannya dalam proses pembangunan tersebut. Berbagai teori dengan paradigmanya masing-masing telah banyak dipergunakan oleh berbagai negara untuk melakukan proses pembangunannya. Peet dan Hartwick (2015) mengelompokkan teori-teori pembangunan ke dalam dua kelompok besar, yaitu pertama, teori pembangunan konvensional; kedua, teori pembangunan tidak konvensional dan teori kritis. Kelompok teori pertama menekankan pembangunan sebagai pertumbuhan ekonomi. Kelompok teori itu merujuk pada bentuk-bentuk ekonomi dan masyarakat yang berdasarkan pada pengalaman Eropa Barat yang tidak dapat dilepaskan dari sistem kapitalisme. Kelompok teori kedua merupakan antitesis dari kelompok teori pembangunan pertama. Kelompok ini menolak sistem kapitalisme dalam pembangunan. Terdapat dua aliran dalam kelompok ini, yaitu yang dipengaruhi oleh pemikiran marxis dan yang tidak berada pada garis pemikiran marxis. Teori-teori yang berada dalam kelompok teori pembangunan konvensional adalah teori ekonomi klasik, teori ekonomi neoklasik, teori keynesian, teori liberalisme, teori neoliberalisme, dan teori modernisasi. Sementara teori-teori yang berada dalam kelompok teori pembangunan tidak konvensional dan teori kritis adalah teori ketergantungan, teori sistem dunia, teori regulasi, teori postkolonial, teori poststruktural, teori postdevelopmentalisme, dan teori pembangunan feminisme (Peet dan Hartwick, 2015). Selanjutnya Peet dan Harwick (2015) mengajukan teori modernisme kritis, sebagai alternatif teori pembangunan.

Perkembangan teori-teori tersebut dikemukakan oleh Willis (2005) serta Telfer dan Sharpley (2008). Pembangunan sering kali dikaitkan dengan konsep modernitas (Willis, 2005). Terminologi modernitas merujuk pada bentuk-bentuk ekonomi dan masyarakat yang berdasar pada pengalaman Eropa Barat. Pada awal perkembangannya di 1950-an sampai 1960an pembangunan banyak dipengaruhi oleh paradigma. Teori yang muncul antara lain Teori Tahapan-tahapan Pertumbuhan dari Rostow dan Teori Difusi yang menyatakan bahwa pembangunan ekonomi di negara-negara maju akan menimbulkan dampak positif pada pertumbuhan ekonomi negara-negara miskin (underdevelopment) dan negara berkembang (developing countries). Teori-teori ini kemudian mendapat "perlawanan" karena dirasakan banyak kelemahan. Muncullah teori-teori dengan paradigma Ketergantungan seperti Teori Neo Kolonialisme yang menyatakan bahwa kemiskinan negara-negara ketiga karena dieksploitasi oleh negara maju, dengan variannya Teori Dualisme dan Teori Strukturalisme. Pada pertengahan tahun 1970-an sampai tahun 2000an berkembang teori-teori dengan paradigma Ekonomi Neo Liberalisme, seperti Teori Pasar Bebas (Free Market Theory), Teori Penyesuaian Struktural (Structural Adjustment Theory), dan Teori Sistem Dunia (World System Theory). Pada saat yang sama juga berkembang teori dengan paradigma Pembangunan Alternatif, seperti Teori Kebutuhan Dasar (Basic Needs Theory), Teori Akar Rumput (Grassroots Theory), Teori Gender (Gender Theory), dan Teori Pembangunan Berkelanjutan (Sustainable Development) (Willis, 2005; Telfer dan Sharpley, 2008).

Semua teori itu pada dasarnya berupaya untuk mewujudkan kesejahteraan masyarakat melalui pembangunan. Berkaitan dengan pembangunan masyarakat itu, dalam sejarah Indonesia ada seorang pemimpin masyarakat Indonesia yang sangat menaruh perhatian besar pada pembangunan masyarakat. Pembangunan 
yang dijalankannya berangkat dari pemikirannya sendiri, karena teori-teori tersebut belum muncul. Ia sudah memikirkan dan menjalankan pemikirannya supaya masyarakatnya menjadi sejahtera dan maju. Pemimpin pribumi itu adalah Pangeran Adipati Aria Soeria Atmadja, bupati Kabupaten Sumedang periode 1883-1919. Pemikirannya itu dituliskan dalam buku yang berjudul Di Tioeng Memeh Hoedjan (Di Payung Sebelum Hujan). Meskipun pemikirannya muncul pada akhir abad XIX dan awal abad XX, namun pemikirannya itu masih relevan untuk dilaksanakan pada masa kini, terutama nilainilainya.

Dalam artikel ini didiskusikan pemikiranpemikirannya yang terdapat dalam naskah buku tersebut. Pertanyaan yang akan didiskusikan adalah apa pemikiran pembangunan yang dinyatakan Pangeran Adipati Aria Soeria Atmadja dalam buku Di Tioeng Memeh Hoedjan dan apa makna dari pemikirannya itu? Adapun tujuan penulisan artikel ini adalah untuk menggali dan memahami pemikiran Pangeran Adipati Aria Soeria Atmadja dalam buku Di Tioeng Memeh Hoedjan yang berkaitan dengan pembangunan.

\section{METODE}

Penelitian untuk membangun artikel ini menggunakan metode kualitatif dengan pendekatan hermeneutika (Ahimsa-Putra, 2007). Pengumpulan datanya menggunakan teknik studi kepustakaan (Zed, 2008). Data primer berupa pernyataan-pernyataan Pangeran Adipati Aria Soeria Atmadja yang dinyatakan dalam buku Di Tioeng Memeh Hoedjan. Dengan pendekatan itu naskah buku tersebut diinterpretasikan atau ditafsirkan. Dalam perspektif hermeneutika, naskah yang berupa teks itu merupakan ekspresi pengalaman mental pengarangnya. Oleh karena itu, dengan menginterpretasikannya akan didapatkan pemahaman terhadap pengalaman mental pengarangnya. Kegiatan menginterpretasikan adalah proses yang bersifat "triadik", yaitu mempunyai tiga sisi yang saling berhubungan (Sumaryono, 1999). Ketiga sisi itu adalah teks naskah, pengalaman mental pengarangnya, dan subjek yang menginterpretasikan (peneliti).
Untuk memulai proses hermeneutika, peneliti berusaha menempatkan diri secara objektif dan subjektif dalam posisi pengarang. Secara objektif dengan mempelajari bahasa yang dipergunakan pengarang, dan secara subjektif dengan mempelajari kehidupan dan pemikiran pengarang. Untuk itu, Schleiermacher (Palmer, 1980; Schmidt, 2010) menyatakan, bahwa harus dilakukan interpretasi terhadap dua aspek, yaitu aspek kebahasaan beserta kelengkapannya (yang merupakan sisi objektif) dan aspek psikologi yang berupa ide subjektif pengarang (yang merupakan sisi subjektif). Hubungan antara kedua aspek tersebut adalah hubungan dialektis.

Untuk menginterpretasi aspek kebahasaan diperlukan penguasaan dan pengetahuan bahasa yang digunakan oleh pengarangnya. Hal tersebut menjadi syarat utama untuk dapat menginterpretasikan suatu teks. Schleiermacher (Schmidt, 2010) menyatakan, bahwa keberadaan pengarang dalam sejarah, pendidikan pengarang, dan pekerjaan pengarang menentukan penggunaan bahasanya. Oleh karena pengarang bermaksud untuk berkomunikasi, maka bahasa yang digunakannya adalah bahasa yang dipahami oleh pembacanya. Teks dalam naskah Di Tioeng Memeh Hoedjan menggunakan bahasa Sunda sebagai bahasa pengantarnya yang ditulis orang Sunda dengan kelas sosial menak (bangsawan) serta berkedudukan sebagai pemimpin masyarakat (bupati). Gagasan-gagasan dalam naskah tersebut ditujukan kepada rakyatnya agar mereka dapat hidup sejahtera.

Interpretasi psikologi bertujuan untuk merekonstruksi pemikiran pengarang dan cara pemikiran itu diekspresikan. Pengetahuan yang baik terhadap pengarangnya akan semakin mempermudah untuk memahami alur pemikirannya. Untuk mendapatkan pengetahuan tentang pengarangnya, peneliti memosisikan diri pada masa pengarang itu hidup dan masa pembacanya. Hal itu berarti peneliti harus memahami sejarah ketika naskah itu dibuat. Dengan memiliki pengetahuan tentang pengarangnya, maka dapat dipahami pemikiran sekunder pengarang serta apa yang tidak diungkapkan secara eksplisit dalam naskah.

Teknik analisis untuk mendapatkan maknanya adalah dengan menggunakan 
lingkaran hermeneutika (Palmer, 1980; Schmidt, 2010). Prosesnya dimulai dari membaca secara keseluruhan naskah buku Di Tioeng Memeh Hoedjan untuk mendapatkan gambaran keseluruhan. Dari membaca keseluruhan itu diperoleh gagasan utama, arah bahasan, dan bagian-bagian yang akan dikaji, yang dalam hal ini pemikiran pembangunan. Selanjutnya dianalisis bagian-bagian yang dikaji itu dengan menginterpretasi aspek kebahasaannya dan aspek psikologinya. Kedua aspek tersebut didialektikkan, lalu sintesisnya didialektikkan dengan gambaran keseluruhan naskah. Sintesis antara bagian dan keseluruhan itu adalah merupakan makna dari bagian itu. Proses tersebut terus dilakukan pada bagian-bagian lainnya.

\section{HASIL DAN PEMBAHASAN}

\section{Riwayat Singkat Pangeran Adipati Aria Soeria Atmadja}

Pangeran Aria Soeria Atmadja dilahirkan di Sumedang pada Kamis Wage 11 Januari 1851. Ayahnya adalah Pangeran Aria Soeria Koesoema Adinata, bupati Sumedang yang sedang menjabat ketika itu, dan ibunya bernama Raden Ayu Ratnaningrat. Ketika baru lahir sampai usia anakanak, Pangeran Aria Soeria Atmadja bernama Raden Sadeli. (Herlina, 2008). Menurut kepercayaan tradisional masyarakat, seseorang yang lahir pada hari Kamis Wage memiliki karakter hati-hati, dapat memesona orang lain dengan penampilan dan sopan santunnya, serta menghargai orang lain. Seseorang yang lahir pada hari tersebut memiliki cita-cita yang sangat tinggi dan dengan karakternya itu biasanya cita-citanya akan terwujud. Dalam perjalanan kehidupannya kemudian, karakter seperti yang ada dalam kepercayaan tradisional itu, terwujud dalam karakter Raden Sadeli selama ia menjalani hidupnya.

Dalam menjalani kehidupannya, seorang menak (bangsawan) yang ideal akan menjalani tiga tahap kehidupan. Tahap pertama dari pertumbuhannya ditandai dengan mencoba pengalaman hidup prihatin, belajar disiplin, dan hidup sederhana. Tahap kedua ditandai dengan memikul tanggung jawab dan melaksanakan kewajiban yang diiringi oleh usaha meraih kedudukan dan keagungan materi. Tahap ketiga ditandai dengan mengalihkan minatnya dari dunia kehidupan materi ke dunia kehidupan spiritual (Moertono, 1985).

Sebagai seorang anak bupati, Raden Sadeli diharapkan oleh orang tuanya, Pangeran Aria Soeria Koesoema Adinata, untuk meneruskan kedudukannya sebagai bupati. Oleh karena itu, ayahnya mendidik Raden Sadeli supaya bisa menjadi bupati yang dapat membawa kebaikan dan kesejahteraan pada rakyatnya. Sifat-sifat kepemimpinan ideal diajarkan kepada Raden Sadeli oleh orang tuanya. Untuk itu, pada tahap pertama, Raden Sadeli dididik sisi moralnya dengan diberikan pendidikan agama Islam. Raden Sadeli belajar mengaji Al Qur'an dan kemudian menempuh pendidikan pesantren di Pesantren Cipicung, yang sekarang dikenal dengan nama Pesantren Asyrofuddin Conggeang. Melalui pendidikan agama Islam itu Raden Sadeli dibekali ajaran-ajaran moral yang kelak bermanfaat ketika ia mendarmabaktikan hidupnya pada rakyatnya. Selain itu, ia juga menekuni pendidikan di sekolah.

Dalam kehidupan seorang menak yang akan dipersiapkan menjadi pejabat birokrasi, ia akan menempuh dua tahap pendidikan, yaitu pertama, tahap mengabdi; dan kedua, tahap magang/membantu (Moertono, 1985). Ketika seorang anak menak berusia 12 sampai 15 tahun, ia akan mengabdi kepada satu keluarga, seseorang, atau beberapa orang untuk belajar kehidupan. Tujuan dari pendidikan pada tahap mengabdi ini adalah untuk mendapat pengetahuan dan melatih kepekaan serta ketrampilan dengan cara mengalami sendiri segala bentuk kehidupan yang ada dalam masyarakat. Pada tahap pertama ini, ia akan mempelajari hal-hal yang berkaitan dengan ketrampilan (kemampuan motorik), seperti menunggang kuda, menggunakan senjata, kesenian, menulis, membaca, dan sebagainya. Ia pun akan mempelajari tata krama, nilai-nilai sosial, dan pelajaran-pelajaran lain yang bersifat afektif. Selain itu, ia pun akan menerima pelajaran lain yang berkaitan dengan kehidupan sehari-hari dan peristiwa yang terjadi sehari-hari, baik yang 
bersifat positif maupun negatif. Tahap berikutnya adalah tahap magang, yaitu bekerja di birokrasi pemerintahan tetapi belum mempunyai jabatan.

Sebagai menak, tampaknya Raden Sadeli menempuh dua tahapan pendidikan tersebut. Namun belum diperoleh sumber berkenaan dengan tahapan mengabdi. Bisa jadi tahapan mengabdinya dilakukan di tempat tinggalnya di pendopo kabupaten dengan para abdinya. Sementara tahap magang dilakukan oleh Raden Sadeli ketika ia bekerja sebagai kliwon di Sumedang. Pekerjaan itu dijalaninya ketika berumur 18 tahun selama 1,5 tahun, yaitu mulai Agustus 1869 sampai Februari 1871. Kliwon adalah satu jabatan atau pekerjaan yang berada di kawedanaan. ${ }^{1}$

Setelah menjalani pekerjaannya sebagai kliwon di Sumedang, pada 7 Februari 1871 Raden Sadeli ditugaskan oleh Pemerintah Hindia Belanda menjadi wedana Ciawi. Pekerjaan ini merupakan jabatan pertamanya dalam birokrasi pemerintahan. Pada saat itu, tampaknya Raden Sadeli mengganti namanya menjadi Raden Soeria Atmadja. Raden untuk menunjukkan gelar kebangsawanan yang diterima sejak lahir, sedangkan Soeria Atmadja ${ }^{2}$ mengandung makna keturunan Soeria yang agung. Penggantian nama itu bermakna bahwa seorang menak yang sedang dipersiapkan menjadi pejabat birokrasi pemerintahan telah mampu dan siap untuk mengemban jabatan dalam birokrasi pemerintahan. Penggantian nama ketika menjabat dalam birokrasi pemerintahan sudah lazim pada kerajaan-kerajaan di Jawa, termasuk Kerajaan Mataram Islam $^{3}$ dan daerah-daerah yang dipengaruhinya, seperti Kabupaten Sumedang. Dalam nama itu biasanya terkandung makna keagungan, kewibawaan, dan legitimasi. Begitu juga dengan nama Raden Soeria Atmadja mengandung unsur legitimasi bahwa ia adalah keturunan dari bupati-bupati Sumedang sebelumnya yang agung dan berwibawa.

Selama hampir lima tahun Raden Soeria Atmadja menjabat sebagai wedana Ciawi, Pemerintah Hindia Belanda melihat kecakapan dan kepemimpinannya yang menonjol. Oleh karena itu, pada 29 November 1875 ia dipromosikan menjadi patih Afdeling Sukapura Kolot yang berkedudukan di Mangunreja. Pada
13 Maret 1879, atas kepemimpinan dan kecakapannya yang menonjol selama memimpin Afdeling Sukapura, Raden Soeria Atmadja dianugerahi gelar "rangga" oleh Gubernur Jenderal Hindia Belanda, sehingga namanya menjadi Raden Rangga Soeria Atmadja. Gelar "rangga" adalah gelar yang diberikan karena menduduki jabatan birokrasi di bawah bupati (Berg, 1902).

Jabatan patih Afdeeling Sukapura Kolot dijalaninya selama tujuh tahun satu bulan. Pada 30 Desember 1882 Raden Rangga Soeria Atmadja diangkat oleh Gubernur Jenderal Hindia Belanda menjadi Bupati Sumedang menggantikan ayahnya, Pangeran Aria Soeria Koesoema Adinata, yang wafat pada 22 September 1882. Pada waktu yang bersamaan ia pun mendapat gelar "tumenggung" dari Gubernur Jenderal Hindia Belanda, sehingga namanya menjadi Raden Tumenggung Soeria Atmadja. Gelar tumenggung diberikan kepada seseorang bila menjabat sebagai bupati (Berg, 1902). Raden Tumenggung Soeria Atmadja dilantik sebagai Bupati Sumedang pada 31 Januari 1883.

Selama menjalankan tugasnya sebagai bupati, Raden Tumenggung Soeria Atmadja mendapat beberapa penghargaan dari Gubernur Jenderal Hindia Belanda. Penghargaan itu adalah (1) Bintang Emas "de Groote Gouden Ster" yang diberikan pada 21 Agustus 1891; (2) Bintang "Officier van de Orde van Oranje Nassau" yang diberikan pada 27 Agustus 1903; dan (3) Bintang Agung "Ridder der Orde van den Nederlandschen Leeuw" "yang diberikan pada 17 September 1918. Selain itu, ia juga mendapatkan penghargaan lain, yaitu (1) pada 31 Agustus 1898 gelar jabatannya ditingkatkan dari tumenggung menjadi adipatí 5 , sehingga namanya menjadi Raden Adipati Soeria Atmadja; (2) Pada 26 Agustus 1905 mendapat penghargaan "Songsong Kuning” (Payung Kuning); (3) Oleh karena mendapat penghargaan "Songsong Kuning", maka pada 29 Agustus 1905 gelar jabatannya ditambah dengan "aria", sehingga namanya menjadi Raden Adipati Aria Soeria Atmadja; (4) Pada 26 Agustus 1910 gelar kebangsawanannya ditingkatkan oleh Gubernur Jenderal Hindia Belanda dari "raden" menjadi "pangeran", 
sehingga namanya menjadi Pangeran Adipati Aria Soeria Atmadja. Gelar kebangsawanan pangeran itu diberikan kepada Raden Adipati Aria Soeria Atmadja karena ia ditugaskan sebagai bupati wedana, yaitu koordinator bupati-bupati di Keresidenan Priangan. Oleh karena mendapat gelar kebangsawanan "pangeran", maka simbol kebangsawanan dan jabatannya pun ditingkatkan. Untuk itu ia mendapat penghargaan "Songsong Emas" (payung mas). Penghargaanpenghargaan itu diberikan karena kecakapan, kepemimpinan, dan prestasi yang sangat baik dalam memimpin dan menyejahterakan rakyat Sumedang.

Jabatan bupati dijalani oleh Pangeran Adipati Aria Soeria Atmadja sekitar 36 tahun. Pada 17 April 1919 ia pensiun atas permintaan sendiri karena merasa telah lanjut usia. Ia menyadari bahwa kemampuan fisiknya sudah tidak mungkin lagi untuk dapat mengimbangi dinamika perubahan masyarakat. Ia kemudian lengser keprabon dan lebih mendalami kehidupan keagamaan. Setelah pensiun ia tinggal di Sindang Taman, Desa Sindangjati. Pada 21 April 1921 Pangeran Adipati Aria Soeria Atmadja menunaikan ibadah haji dan tidak pernah kembali ke Sumedang. Ia wafat di tanah suci Mekah dan dikebumikan di pemakaman Ma'ala pada 1 Juni 1921. Oleh karena meninggal di tanah suci Mekah, maka masyarakat Sumedang kemudian memberi julukan kepada Pangeran Adipati Aria Soeria Atmadja sebagai "Pangeran Mekah”. Ia meninggalkan istrinya, Raden Ayu Radja Ningrum, dan putrinya, Raden Ayu Djogdjainten Djoebaedah.

\section{Peranan Pangeran Adipati Aria Soeria Atmadja dalam Pembangunan Masyarakat Kabupaten Sumedang}

Selama menjabat sebagai pejabat birokrasi pemerintahan, sejak menjadi kliwon sampai bupati, Pangeran Adipati Aria Soeria Atmadja selalu berupaya meningkatkan kesejahteraan rakyat yang dipimpinnya, sehingga tidak mengherankan bila ia banyak mendapat penghargaan dari Pemerintah Hindia Belanda. Ia sangat sadar bahwa rakyat yang dipimpinnya hidup dari pertanian, peternakan, dan perikanan.
Oleh karena itu, ia berupaya meningkatkan taraf hidup rakyatnya melalui bidang-bidang itu. Dalam membuat kebijakan dan program pembangunannya itu, ia sangat memperhatikan lingkungan hidup, kehidupan budaya, serta kehidupan sosial masyarakatnya. Dengan kata lain, Pangeran Adipati Aria Soeria Atmadja sudah menggunakan pemikiran yang berkaitan dengan pembangunan yang berkelanjutan dalam membuat kebijakan dan program pembangunannya. Beberapa kebijakan dan program pembangunan yang memperhatikan pembangunan yang berkelanjutan akan diuraikan pada bagian berikut.

Di bidang pertanian, penduduk Kabupaten Sumedang mengonsumsi nasi sebagai makanan pokoknya, tetapi wilayah geografis Kabupaten Sumedang bergunung-gunung dengan banyak lereng dan tebing, Pangeran Adipati Aria Soeria Atmadja lalu membuat program pembuatan sawah yang bertangga atau sengked pada tanahtanah yang miring. Pada masa kini sawah seperti itu dinamakan sawah terrasering. Ia pun mengembangkan lumbung-lumbung di desadesa untuk menghadapi masa paceklik. Lumbung-lumbung itu banyak dibuat masyarakat Sunda untuk menyimpan padi. Untuk meningkatkan produksi non beras, ia berupaya untuk meningkatkan produksi tanaman aren (enau) dengan jalan melindungi binatang luwak. Melalui luwak ini jumlah pohon aren dapat meningkat secara alami (Herlina, 2008).

Dengan membuat sawah terrasering, maka akan dapat meminimalkan erosi. Dengan demikian, maka dapat dihindari bencana banjir dan longsor. Upaya mencegah banjir juga dilakukan dengan memberlakukan hutan tutupan yang disebut dengan Leuwi Tutupan. Di hutan tutupan ini dilarang menebang pohon dan merusak ekosistemnya. Dengan pencegahan banjir, maka produksi pertanian akan sesuai dengan harapan. Ia pun meminta rakyatnya yang tinggal di pinggir jalan untuk menanam tanaman yang kayunya cocok untuk pembuatan jembatan dan bangunan. Selain kayunya bisa digunakan, akar-akar tanaman itu dapat menahan tergerusnya tanah oleh air (Herlina, 2008).

Di bidang perikanan, Pangeran Adipati Aria Soeria Atmadja berupaya untuk menjaga 
keberlangsungan produksi ikan air tawar dengan jalan membuat regulasi-regulasi. Ia membuat aturan tentang lobang jala dengan maksud supaya ikan-ikan yang berukuran kecil tidak terjaring oleh jala. Dengan begitu, maka ikan yang ditangkap melalui jala adalah ikan yang berukuran cukup besar dan sudah dapat dimakan, sedangkan ikan yang kecil akan dapat melanjutkan kehidupannya dan tumbuh menjadi besar. Untuk kemudian ikan dapat dikonsumsi olah rakyat Sumedang. Ia menetapkan aturan tentang waktu menangkap ikan dan tempat menangkap ikan. Ia pun mengeluarkan aturan pelarangan penggunaan racun apa pun ketika menangkap ikan (Herlina, 2008).

Pendidikan dan ahlak yang baik sangat diperhatikan oleh Pangeran Adipati Aria Soeria Atmadja. Menurutnya rakyat Sumedang tidak boleh bodoh, tetapi harus dapat mengembangkan, meningkatkan, dan berinovasi sendiri dalam melakukan produksi pertaniannya. Untuk itu mereka harus dibekali dengan ilmu pengetahuan tentang pertanian. Ia lalu mendirikan sekolah pertanian di Tanjungsari yang kemudian dinamakan Landbouwschool Bojongseungit. Tanah yang dipergunakan untuk sekolah itu berasal dari hibah tanah pribadinya seluas 4,3 ha. Ia pun mengeluarkan uang pribadinya sebesar $f$ 3.000 untuk membangun infrastruktur sekolahnya. Ketika sekolah pertanian itu sudah berjalan, Pangeran Adipati Aria Soeria Atmadja menugaskan murid-murid sekolah pertanian itu untuk menanam tanaman yang berguna bagi rakyat banyak. Hasil tanaman itu kemudian dibelinya dan kemudian dibagikan kepada rakyatnya sebagai bibit (Herlina, 2008). Selain itu, ia pun mendirikan sekolah tingkat dasar di desa-desa supaya semakin banyak rakyat Sumedang yang berpendidikan. Ia belum dapat mendirikan sekolah tingkat lanjutan karena regulasi ketika itu tidak memungkinkan. Sekolahsekolah itu tidak akan berjalan dengan baik bila tidak ada guru yang mengelolanya. Oleh karena itu, kesejahteraan sosial dan ekonomi guru sangat diperhatikannya, antara lain dengan memberikan penghasilan yang baik dan insentif-insentif. Murid-muridnya pun mendapat perhatian dari Pangeran Adipati Aria Soeria Atmadja. Ia memberikan hadiah kepada siswa-siswa yang berprestasi (Herlina, 2008).

Akhlak yang baik sangat diperhatikan oleh Pangeran Adipati Aria Soeria Atmadja. Menurutnya, peningkatan kesejahteraan harus diimbangi dengan akhlak dan moral yang baik. Oleh karena itu, ia sangat menaruh perhatian besar pada bidang keagamaan, khususnya agama Islam. Sejak menjabat sebagai patih di Afdeeling Sukapura Kolot, ia banyak mewakafkan tanahnya untuk pembangunan masjid dan pesantren. Beberapa tanah Pangeran Adipati Aria Soeria Atmadja di Tasikmalaya yang diwakafkannya, sekarang berdiri Masjid Agung Tasikmalaya dan Pesantren Cigalontang. Begitu pula halnya ketika menjabat sebagai bupati Sumedang selama 36 tahun. Ia pun mengembangkan almamaternya, Pesantren Asyrofuddin, dan pesantren-pesantren lainnya. Bahkan tidak hanya itu, ia pun mengundang kyai-kyai dan guru-guru agama dari kabupaten lain untuk mengajarkan agama Islam di Kabupaten Sumedang (Herlina, 2008).

Di bidang perekonomian Pangeran Adipati Aria Soeria Atmadja mendirikan Bank Desa, Bank Priyayi, Volkskredietbank yang merupakan cikal bakal Bank BRI, serta menganjurkan cara hidup rik-rik gemi, yaitu hidup berhemat dan tidak boros. Maksud pendirian bank-bank itu adalah supaya rakyat dan pegawai dapat melakukan kegiatan simpan pinjam uang untuk meningkatkan kesejahteraan hidupnya. Di bidang perhubungan, ia membangun prasarana jalan di beberapa tempat. Satu di antaranya yang terpenting adalah pembangunan jalan Cadas Pangeran di bagian bawah tahun 1908 yang sekarang menjadi jalan utama yang menghubungkan kota Bandung dengan kota Sumedang. Jalur kereta api dari Rancaekek Tanjungsari sampai Tunggul Hideung - Citali difasilitasinya supaya perekonomian rakyat Kabupaten Sumedang semakin bertambah baik. Begitu juga halnya dengan prasarana telekomunikasi, yaitu dibangunnya gedung kantor telepon. Di bidang keamanan, ia mengeluarkan kebijakan agar di setiap desa dibangun gardu-gardu ronda. Melalui gardugardu tersebut, keamanan lingkungan di setiap desa dapat dijaga (Herlina, 2008). 
Di bidang politik, pemikiran Pangeran Adipati Aria Soeria Atmadja tidak lagi sebatas Kabupaten Sumedang, tetapi sudah berskala makro untuk kepentingan seluruh bangsa yang ada di Nusantara. Ia mengajukan usulan kepada Pemerintah Hindia Belanda agar rakyat dilatih menggunakan senjata dengan maksud supaya rakyat dapat dilibatkan dalam pembelaan negara, bila terjadi serangan dari luar, terutama di daerahnya masing-masing. Usulannya itu dituangkannya dengan judul Indie Weerbaar (Pertahanan Hindia). Namun usulannya itu ditolak Pemerintah Hindia Belanda karena pemerintah khawatir bila rakyat terlatih menggunakan senjata, maka keahliannya itu akan digunakan untuk melawan pemerintah sendiri.

Semua yang telah dilakukannya selama mengabdi sebagai pegawai pemerintah Hindia Belanda, sejak dari kliwon sampai menjadi bupati wedana, serta hasil didikan orang tuanya sebagai sosok menak, dituangkan dalam buku yang berjudul Di Tioeng Memeh Hoedjan. Buku itu ditulis dengan bahasa yang santun dan halus. Namun demikian, Pemerintah Hindia Belanda menangkap adanya kesadaran nasionalisme dalam diri Pangeran Adipati Aria Soeria Atmadja mengingat sudah muncul gagasan akan kemerdekaan dalam bukunya itu. Supaya gagasan tersebut tidak menyebar ke masyarakat, Pemerintah Hindia Belanda melarang peredaran buku tersebut.

\section{Naskah Buku Di Tioeng Memeh Hoedjan}

Naskah buku Di Tioeng Memeh Hoedjan yang diperoleh bukan merupakan naskah asli, tetapi berupa fotokopi yang entah sudah turunan fotokopi ke berapa. Oleh karena merupakan fotokopi dari fotokopi seperti itu, maka ada beberapa informasi yang tidak jelas. Tahun terbit yang ada di halaman depan tidak dapat dibaca dengan pasti. Begitu juga dengan penerbitnya. Namun begitu, tahun terbitnya bisa diperkirakan sekitar 1918-1921, yaitu ketika masa akhir jabatannya sebagai bupati dan sebelum ia berangkat ibadah haji. Hal tersebut didasarkan dari isi buku itu yang merupakan ekstraksi dari yang telah dikerjakan. Pesan-pesan yang disampaikan dalam buku ini tidak langsung pada yang dimaksud, tetapi dalam bentuk cerita burung yang datang ke suatu hutan yang baru didatanginya. Burung itu dianalogikan sebagai bangsa Belanda yang datang ke Nusantara.

Buku tersebut terdiri atas tiga bagian dengan bahasa Sunda sebagai bahasa pengantarnya. Bagian pertama dengan judul "Baris Ka Sagala Baroedak Soenda" (Untuk Semua Anak-anak Sunda) yang merupakan pengantar buku tersebut berisi pesan Pangeran Adipati Aria Soeria Atmadja kepada anak-anak Sunda untuk mengikuti pesan-pesan yang disampaikannya dalam buku tersebut. Bagian kedua berjudul "Dongeng" (Cerita) mengemukakan tentang cerita seekor burung yang datang ke suatu hutan yang belum dikenalnya yang kemudian bersarang di hutan itu. Hutan yang didatanginya itu berisi berbagai burung yang hidup berkelompok dan masingmasing kelompok mempunyai pemimpinnya masing-masing. Dengan berbagai upaya, satu demi satu kelompok burung itu menjadi bawahannya. Akhirnya burung pendatang itu dapat menguasai hutan itu dan menjadi satusatunya raja burung di hutan itu.

Bagian ketiga menjelaskan maksud dari bagian-bagian yang disampaikan pada bagian kedua. Di bagian ini disebutkan bahwa yang dimaksud burung pendatang itu adalah bangsa Belanda. Hutan yang didatanginya adalah Nusantara. Berbagai jenis burung yang hidup berkelompok di hutan adalah bangsa pribumi di Nusantara yang terdiri atas berbagai suku bangsa. Kelompok-kelompok burung yang dipimpin oleh rajanya sendiri itu adalah kerajaan-kerajaan berdaulat yang ada di Nusantara.

Dijelaskan pula pada bagian ketiga ini bahwa pada mulanya bangsa Belanda datang ke Nusantara adalah untuk berdagang dengan bangsa pribumi. Dalam proses perdagangan itu mereka melakukannya atas dasar saling memercayai. Bangsa Belanda pun mempunyai musuh bersama dengan bangsa pribumi, yaitu Inggris dan Portugis, karena mereka melakukan perdagangan secara monopoli yang merugikan bangsa pribumi dan juga bangsa Belanda. Dalam perkembangannya hubungan perdagangan antara kerajaan-kerajaan pribumi yang berdaulat dengan bangsa Belanda yang didasarkan atas 
saling memercayai berubah menjadi penguasaan oleh bangsa Belanda. Satu demi satu kerajaan berdaulat di Nusantara kehilangan kedaulatannya dan tunduk pada bangsa Belanda. Akhirnya seluruh kerajaan di Nusantara menjadi kerajaan taklukan bangsa Belanda dan bangsa Belanda akhirnya menjadi satu-satunya raja yang berdaulat di Nusantara. Namun begitu, bangsa Belanda yang sudah menjadi raja di Nusantara itu tetap memberikan kesempatan kepada bangsa pribumi untuk menjalankan pemerintahannya sendiri sesuai dengan sistem sosial budayanya masing-masing, sepanjang tidak menentang secara politik kepada Pemerintah Belanda. Dalam kondisi Nusantara seperti itu, Pangeran Adipati Aria Soeria Atmadja mengajukan pemikiran tentang pembangunan bagi kemajuan rakyat pribumi melalui bahasa Sunda yang santun.

\section{Pemikiran dan Makna Pembangunan Pangeran Adipati Aria Soeria Atmadja}

Pemikiran Pangeran Adipati Aria Soeria Atmadja yang berkaitan dengan pembangunan yang tertuang dalam buku Di Tioeng Memeh Hoedjan berasal dari pengalaman hidupnya selama 50 tahun menjadi birokrat yang kemudian diekstraksikan ke dalam buku tersebut. Pemikirannya itu memadukan aspek strategi, materi, dan moral. Menurutnya, setiap proses pembangunan yang dilakukan harus dilandasi dengan moralitas yang baik. Bagi Pangeran Adipati Aria Soeria Atmadja, pembangunan adalah upaya untuk menjadikan kehidupan rakyat banyak menjadi lebih baik dari pada masa sebelum dilakukan pembangunan. Maksud kehidupan yang lebih baik adalah adanya peningkatan yang seimbang antara kehidupan ekonominya yang dibarengi oleh peningkatan kehidupan sosial, budaya, dan keimanan pada Tuhan. Jadi pembangunan tidak hanya mengenai aspek fisiknya, tetapi juga aspek sosial, budaya, dan keimanan. Dasar dari pemikirannya adalah bahwa dalam melakukan pembangunan untuk menyejahterakan rakyat harus berlandas pada niat yang tulus dan pantang menyerah, tetapi tidak mengumbar nafsu keduniawian, yang semuanya itu dibarengi dengan keimanan dan ketakwaan pada Tuhan. Sikap itu harus dimiliki oleh semua pihak yang terlibat dalam pembangunan itu, karena pembangunan itu tidak dapat dilakukan hanya oleh satu pihak saja, tetapi harus ada sinergi antara pemerintah atau pemodal yang menjalankan program pembangunan dengan masyarakat yang menjadi sasaran pembangunan. Jadi dalam hal ini masyarakat yang menjadi sasaran pembangunan juga turut aktif dalam proses pembangunan itu. Pembangunan tidak hanya menjadi domain penguasa atau yang mempunyai modal, tetapi juga seluruh rakyat.

Pembangunan yang dilandasi oleh niat yang tulus dan tidak mengumbar nafsu keduniawian mempunyai makna bahwa semua pihak yang terlibat dalam pembangunan harus mempunyai niat yang bersih, jujur, dan terbuka, baik pada dirinya dan juga orang lain. Dengan sikap itu akan menghindarkan dari perbuatan serakah, mencari keuntungan besar yang tidak wajar, berbuat curang, berbuat tidak adil, dan selalu memperhatikan masyarakat yang akan dibangunnya. Bagi pihak pemerintah dan pemodal akan terbuka, transparan, jujur, tidak arogan, tidak memaksakan kehendaknya yang bertentangan dengan masyarakat yang menjadi sasaran pembangunan. Ia menyadari akan kekurangan dan kelebihannya. Bagi masyarakat yang menjadi sasaran pembangunan akan bersikap membantu dan menerima kelebihan dan kekurangan pembangunan itu, yang kemudian secara bersama-sama dengan pelaku pembangunan lainnya berupaya untuk memperbaiki dan meningkatkan kualitas dan kuantitasnya. Masyarakat tidak hanya menuntut, tetapi terlibat langsung dalam proses pembangunan itu karena menyadari bahwa pembangunan itu adalah untuk kepentingan dirinya. Masyarakat pun menyadari bahwa pemodal mencari keuntungan dan pemodal pun tidak akan mencari keuntungan yang tidak wajar.

Pesan jangan serakah dan mengambil keuntungan yang tidak wajar diungkapkan sebagai berikut.

“... Taja deui kahajangna ngan dapon bisa djongdjon dagang sarta toemaninah ngoekoed oentoeng anoe sakitoe gedena bae; tapi doemeh maranehanana tambah-tambah santosa, djeung boga adat hawek, koe Radja- 
Radja Priboemi teh dipikasieun, tapi dipikaidjid nake....r"(Atmadja, t.t.: 21).

(Tidak ada keinginan lain selain tenang dalam berdagang serta nyaman menarik keuntungan yang semakin besar; tapi karena mereka (Belanda) bertambah makmur dan punya sifat serakah, oleh raja-raja pribumi ditakuti dan sangat tidak disukai).

Pesan untuk tidak meninggalkan rakyat yang dipimpinnya semata-mata demi keuntungan besar yang tidak wajar diungkapkan dalam kalimat:

“... Sababaraha lawasna eta bangsa ngahaben bae peperangan sarta loba naker kagorenganana sadjeroning ngaheujeuk nagara djeung tjari oentoeng teh, teu pisan ngoeroes ka djalma-djalma anoe djaradi bawahanana" (Atmadja, t.t.: 22).

(... Setelah beberapa waktu bangsa itu menampakkan kejelekannya dalam mengurus negara dan mencari untung, mereka sama sekali tidak memperhatikan yang menjadi bawahannya).

Pesan untuk memupuk saling percaya berdasar saling keterbukaan dan kejujuran diungkapkan dalam kalimat:

“... Itikad rahajat Walanda di Hindia henteu babari didjoegdjoeganana naon kasoekana naon kadoekana, da henteu ebreh dina beungeutna; kadangkala djelema-djelema teh aja anoe ngandoeng hate, atawa aja noe boga kapanasaran; tah ieu teh hese naker ditalingakeunana" (Atmadja, t.t.: 25).

(... Itikad orang Belanda di Hindia sukar ditebak apa yang disukai dan apa yang tidak disukainya karena tidak tampak pada mukanya; terkadang orang-orang itu ada yang berhati buruk atau ada yang penasaran; hal itu sangat susah dipastikannya).

Proses pembangunan yang dilandasi oleh sikap pantang menyerah tetapi tidak mengumbar nafsu keduniawian mengandung makna, bahwa dalam melakukan proses pembangunan jangan cepat putus asa karena kegagalan akan selalu membayangi. Oleh karena itu, harus selalu melakukan inovasi-inovasi dan selalu menjaga keamanan dan ketenangan, karena dengan suasana aman dan tenang ide-ide kreatif akan lebih mudah dihasilkan. Dalam upaya untuk mendapatkan ide-ide kreatif tentu harus ditunjang oleh badan dan lingkungan yang sehat serta ilmu yang mumpuni. Lingkungan yang harus sehat adalah lingkungan hidup dan lingkungan sosial budayanya. Kegagalan akan dapat dihindarkan bila memperhatikan budaya dan adat istiadat lokal, karena pembangunan yang dijalankan masih tetap berakar pada sistem sosialbudayanya, sehingga masyarakat tidak merasakan adanya sesuatu yang asing. Kegagalan juga akan dapat dihindari bila rakyat yang menjadi obyek pembangunan adalah rakyat yang berpendidikan dan pintar. Maka dari itu, rakyat yang menjadi objek pembangunan harus dipintarkan karena bila pintar maka tidak akan dikendalikan orang lain atau dimanfaatkan orang lain. Namun kepintaran itu harus dibarengi oleh moral yang baik supaya ilmu yang dikuasainya bermanfaat.

Pesan bahwa dalam proses pembangunan tidak boleh putus asa dan harus terus melakukan inovasi diungkapkan sebagai berikut:

“... Gambar laoetan, geusan toedoeh djalan, noe katjida keneh pisan koerangna ... Tapi boeboehan oerang Walanda teh, oerang basisir, saba laoet. Lantaran leber wawanen toeroegtoeroeg koe hajang oentoeng gede, nja antoekna mah djalan ka Hindia teh koe maranehanana teu boeroeng kapanggih" (Atmadja, tt: 19-20).

(... Peta untuk menuju Hindia masih kurang, apalagi yang menunjukan jalan... Tetapi karena orang Belanda itu orang pesisir, tetap pergi mengarungi lautan ke Hindia. Disebabkan karena besar keberaniannya dan ingin mendapatkan keuntungan yang besar, akhirnya jalan ke Hindia dapat ditemukannya).

Pesan bahwa semua pihak dalam proses pembangunan harus dapat menahan diri diungkapkan sebagai berikut:

“... Tapi saenggeus perang gede di Europa, anoe leuwih ti opat tahoen lilana koe oerang kaintip, jen adil teh eleh koe pangdjoeroeng napsoe, ..."(Atmadja, t.t.: 29).

(Tetapi setelah perang besar di Eropa yang memakan waktu empat tahun, tampak bahwa adil itu kalah oleh nafsu yang tidak dikendalikan). 
Pesan bahwa dalam menjalankan pembangunan harus sehat badan dan sehat lingkungan diungkapkan sebagai berikut:

“... Pangoeroes djeung Oendang-oendang kesehatan, goenana pikeun ngoeroes kesehatan sadjero wewengkonna (Ngajakeun tjai inoemeun anoe beresih, nambaan anu garering kalawan parentah nagara, malidkeun kokotor-kokotor, tjai oelah ngeunjeumbeu, njaeuran rantja ngarah oelah baoe, djeung tarekah sedjen geusan njingkahkeun bahaja penjakit noelar)" (Atmadja, t.t.: 28).

(Pengurus dan undang-undang kesehatan gunanya untuk mengurus kesehatan sebatas wewenangnya (mengadakan air minum yang bersih, mengobati orang yang sakit, menghanyutkan kotoran, tidak ada air menggenang, menutup rawa supaya tidak bau, menumpas penyakit menular).

Berkaitan dengan kepintaran atau pendidikan, dibahas panjang lebar dalam naskah tersebut. Hal itu menunjukkan bahwa Pangeran Adipati Aria Soeria Atmadja sangat menekankan pendidikan supaya pembangunan dapat berjalan dengan berkesinambungan. Ia ingin menyatakan, bahwa pembangunan akan dapat dilakukan dan akan terus berlanjut bila rakyat pintar dan inti dari pembangunan adalah kepintaran masyarakat yang diiringi moral yang baik. Hal tersebut disampaikan sebagai berikut:

“... Tina tambahna pangarti tea, tangtoe pisan hiroepna bisa leuwih moelja, leuwih gede goenana ka papada djelema, djeung tambah leuwih senang. Lamoen djalma geus mitoemanan metakeun oeteuk, tangtoe pikiranana teh henteu boetek, atina padang, kadang-kadang bisa meunang ilham anoe atjan aja di batoer. Beuki madjoe kapinteranana beuki gampang njiarna sandang pangan. Pangarti teh kawasa! ... Geura eta bae moending anoe sakitoe bedasna da bodo, teu boeroeng digawekeun dipake ngawoeloekoe, atawa ditoempakan koe boedak angon... " (Atmadja, t.t.: 26).

(... Dengan bertambah pintar tentu hidupnya bisa lebih mulya, lebih besar gunanya pada masyarakat, dan akan bertambah sejahtera. Apabila manusia sudah biasa mengolah otak, tentu pikirannya tidak buntu, hatinya lapang, dan kadang-kadang bisa mendapat ilham yang di orang lain tidak ada. Semakin maju kepintarannya maka semakin mudah mencari sandang pangan. Pengetahuan adalah kekuasaan! ... Coba lihat kerbau yang begitu kuatnya tetapi bodoh, karena itu dimanfaatkan untuk membajak sawah atau ditunggangi oleh anak gembala ...).

“... Ari pokona geusan ngamadjoekeun djalma bodo, soepaja koeat djeung soepaja boga djeudjeuhan, nja eta koedoe ditambah kanjahona, koe papatah". (Atmadja, t.t.: 26). (... Pada pokoknya memajukan orang bodoh supaya kuat dan punya pegangan, yaitu harus ditambah pengetahuannya oleh ilmu).

“... Enggoning oerang ngawarah baroedak, eta henteu tjoekoep koe dibere pangarti dipinterkeun bae, tapi koedoe djeung dibaroeng koe pangasoeh sangkan hade hatena, soepaja hiroepna salamet djeung aja mangpaatna ka djalma loba.... Geura oepama ajeuna anak maneh disakolakeun ka hidji goeroe, anoe geus loma toer resepeun ka eta boedak, toeroeg- toeroeg eta goeroe metakeunana atoeran ngadjar aloes prakna $\mathrm{ka}$ eta boedak; tangtoe bae eta boedak teh gantjang pinter....”. (Atmadja, t.t.: 38).

(... Di dalam kita mendidik anak-anak tidak cukup hanya diberi pengetahuan, tetapi harus dibarengi dengan pendidikan sikap agar baik moralnya, supaya hidupnya selamat dan ada manfaatnya pada masyarakat.... Apabila anak kamu disekolahkan pada seorang guru yang mengajar dengan baik, maka anak itu akan cepat menjadi pintar....).

Sementara pesan untuk memperhatikan budaya lokal dalam pembangunan supaya pembangunan itu berkelanjutan disampaikan sebagai berikut:

“... Ari petana manehanana teh wajahna njampoerkeun maneh djeung anoe masih keneh barodo ngarah njaho kana tabeattabeatna, soepaja babari dipadjoekeunnana jeung dihargaanana.... Tina bisana njampoerkeun maneh, boeboehan djalma ngoembara, oerang Walanda teh miteomanan kana adat Pribumi ....”. (Atmadja, t.t.: 25). 
(... Dalam prakteknya dia (orang Belanda) meleburkan dirinya dengan penduduk pribumi untuk mengetahui tabiat-tabiatnya, supaya mudah memajukannya dan menghargainya... Dari meleburkan diri itu, orang Belanda itu dapat mengetahui adat istiadat pribumi...).

Hal penting yang harus dilakukan dalam pembangunan yang berkelanjutan adalah selalu melakukan evaluasi dan pengawasan. Melalui evaluasi akan diketahui kelemahan-kelemahan dan kekurangan-kekurangan dalam pembangunan itu serta kebutuhan-kebutuhan untuk menutupinya. Dengan begitu, maka kelemahan dan kekurangan itu dapat diatasi. Begitu juga dengan pengawasan. Dalam proses pembangunan harus selalu dilakukan pengawasan supaya berjalan dengan efektif dan efisien. Evaluasi yang harus dilakukan tampak pada:

“... Ngan lamoen bae oerang Walanda djaman harita, tangtoe koe maranehanana kapanggih, loba lampah karoehoenna anoe aloes pinoedjoel, kaselapan koe lampah laip, pendekna aja tjolatna, teu beresih pisan. Tah moen geus kapanggih eta, kakara oerang ngarti kana karepna Walanda djaman kiwari, nja eta hajangeun moepoes eta tjolat tea......(Atmadja, $\mathrm{tt}: 25)$.

(... Namun bila orang Belanda zaman itu tentu dapat ditemukan banyak langkah leluhurnya yang bagus tetapi diselipi oleh langkah salah, pendeknya ada kotornya, tidak bersih sama sekali. Nah bila sudah ketemu, baru orang mengerti bahwa orang Belanda zaman sekarang ingin menghapus kesalahannya....").

Sementara berkaitan dengan pengawasan disampaikan sebagai berikut:

“... Ajeuna koe sakieu oge geus terang, sakoemaha perloena pikeun orang Walanda, anoe sakitu saeutikna, paeh poso neangan daja-oepaja malar tetep pengawasana dina ieu djadjahan-djadjahan anoe sakieu legana....". (Atmadja, t.t.: 29).

(... Sekarang saja sudah tampak sebagaimana perlunya orang Belanda yang sedikit mencari daya upaya agar tetap mengawasi tanah jajahan yang begitu luas....).
Pesan terakhir dari Pangeran Adipati Aria Soeria Atmadja adalah bila proses pembangunan sudah memperhatikan nilai-nilai tersebut dan dijalankan dengan baik, maka langkah selanjutnya berserah diri pada Tuhan Yang Maha Esa. Baginya manusia mempunyai tugas untuk berusaha dan setelah itu minta keridhoan dari apa yang telah dilakukannya kepada Sang Penciptanya. Apabila niatnya baik untuk melakukan pembangunan demi kemajuan bersama, maka hasilnya juga akan mendapatkan apa yang diharapkan. Hal itu diungkapkannya dalam kalimat sebagai berikut:

"Moegi-moegi Goesti noe sipat Rahman djeung Rahim nangtajoengan ka abdi sadaja”. (Atmadja, t.t.: 40).

(Semoga Tuhan yang maharahman dan maharahim meridhoi kita semua).

Dari pernyataan-pernyataan Pangeran Adipati Aria Soeria Atmadja tampak bahwa pemikiran pembangunannya menekankan pada keseimbangan aspek ekonomi, lingkungan, dan sosial-budaya. Hal tersebut sejalan dengan paham Pembangunan Berkelanjutan (Sustainable Development) yang berkembang pada tahun 1980-an (Baker, 2006; Redclift dan Sprigett, 2015). Terdapat tiga aspek yang harus diperhatikan dalam paham Pembangunan Berkelanjutan, yaitu aspek ekonomi, lingkungan, dan sosial-budaya. Ketiga aspek tersebut sejalan dengan pemikiran Pangeran Adipati Aria Soeria Atmadja jauh sebelum paham tersebut berkembang. Hal tersebut menunjukkan bahwa pemikiran Pangeran Adipati Aria Soeria Atmadja telah jauh melampaui pemikiran pada zamannya.

Pada aspek ekonomi, pembangunan harus merata dirasakan oleh seluruh rakyat. Pada aspek lingkungan, pembangunan harus mewujudkan lingkungan hidup yang sehat. Pada aspek sosialbudaya, pembangunan harus berada dalam sistem sosial-budaya masyarakat yang dibangunnya, karena bila tidak, maka pembangunan itu menjadi tidak bermanfaat bagi masyarakatnya. Idealnya ketiga aspek tersebut berjalan seimbang. Untuk mewujudkan hal tersebut, maka pelaksana pembangunan seyogyanya tidak bertindak serakah dan tidak memupuk keuntungan yang tidak wajar, mengedepankan kejujuran dan keterbukaan, dapat menahan diri, terus 
berinovasi, dan terus meningkatkan pengetahuannya.

Menurut Pangeran Adipati Aria Soeria Atmadja, pembangunan akan berkelanjutan bila masyarakatnya terlibat secara aktif dalam proses dan evaluasinya. Supaya gerak pembangunannya seirama, maka perlu dibimbing oleh pemimpin yang adil, jujur, takwa, satu tindakan dan ucapan, dan berwibawa. Keterlibatan masyarakat tersebut penting dilakukan karena pemimpin masyarakat akan berganti, tetapi masyarakat akan tetap ada. Apabila pemimpinnya berganti, maka pembangunan tidak akan terganggu dan akan tetap berjalan sesuai dengan yang diinginkan masyarakatnya. Pembangunan akan berkelanjutan dan dirasakan positif oleh masyarakat bila menyelaraskan pembangunan fisik dan pembangunan moral. Dengan adanya keselarasan tersebut dan dilaksanakan oleh masyarakat sendiri, maka pembangunan yang dijalankan akan terus berjalan karena masyarakat akan mengevaluasi kekurangan-kekurangannya dan akan mencari sendiri solusi-solusinya. Dengan begitu, maka pembangunan akan berkelanjutan.

\section{SIMPULAN}

Dari uraian sebelumnya dapat disimpulkan bahwa pemikiran pembangunan Pangeran Adipati Aria Soeria Atmadja yang terdapat dalam buku Di Tioeng Memeh Hoedjan terformulasikan dari perpaduan antara karakter pribadi dan pengalamannya semasa ia mengabdi pada masyarakat. Pemikiran pembangunannya sejalan dengan paham Pembangunan Berkelanjutan yang baru muncul sekitar satu abad kemudian. Namun bagi Pangeran Adipati Aria Soeria Atmadja, pembangunan tidak hanya sebatas pada pembangunan fisik ketiga aspek Pembangunan Berkelanjutan, tetapi harus dilakukan pembangunan moral juga. Pembangunan juga harus berlandas pada moralitas yang baik, karena bila tidak maka pembangunan itu akan merugikan masyarakat dan tidak berkelanjutan.

Meskipun pemikiran Pangeran Adipati Aria Soeria Atmadja itu muncul pada awal abad $\mathrm{XX}$, namun pemikirannya itu masih relevan untuk dijalankan pada masa kini. Di tengah gencarnya penangkapan pemimpin daerah dan pejabat pemerintahan oleh Komisi Pemberantasan Korupsi karena melakukan penyelewengan dalam proses pembangunan, maka pemikiran Pangeran Adipati Aria Soeria Atmadja ini dapat menjadi bekal dan renungan bagi pelaksana pembangunan, baik di tingkat daerah maupun nasional.

\section{CATATAN}

${ }^{1}$ Dalam struktur pemerintahan pribumi (inlandsche bestuur), kawedanaan (district) adalah wilayah administratif pemerintahan di bawah kabupaten. Wilayah administratif pemerintahan di bawah kawedanaan adalah onderdistrict (sekarang kecamatan). Pejabat lain di kawedanaan selain kliwon adalah kabayan yang dipegang oleh satu orang, dan beberapa orang mantri jajar (Berg, 1902; Moedjanto, 1987; Hardjasaputra, 2004).

${ }^{2}$ Kata atmadja/atmaja berasal dari bahasa Sanskrit yang berarti putra atau anak.

3 Misalnya dalam Kesultanan Ngayogyakarta Hadiningrat di Yogyakarta, nama Sultan Hamengku Buwono X ketika kecil adalah BRM Herjuno Darpito, kemudian berganti nama menjadi KGPH Mangkubumi ketika menjadi pangeran, lalu berubah lagi ketika diangkat menjadi putra mahkota menjadi KGPAA Hamengku Negara Sudibyo Rajaputra Nalendra ing Mataram. Ketika menjadi sultan, nama resminya adalah Sampeyan Dalem Ingkang Sinuhun Kanjeng Sultan Hamengku Buwono Senapati-ingNgalaga Abdurrahman Sayidin Panatagama Khalifatullah ingkang Jumeneng Kaping Sadasa.

${ }^{4}$ Penghargaan tertinggi bagi pejabat pribumi Hindia Belanda.

${ }^{5}$ Gelar adipati adalah gelar jabatan tertinggi bagi pejabat birokrasi pribumi yang biasanya diberikan kepada bupati yang telah menjabat cukup lama dan berprestasi (Berg, 1902).

${ }^{6}$ Di Kerajaan Mataram (Kasultanan Yogyakarta dan Kasunanan Surakarta) terdapat empat tingkatan gelar kebangsawanan, yaitu secara berurutan dari yang tertinggi: sultan atau sunan, pangeran, raden mas, dan raden. Sementara di Priangan, hanya terdapat dua kelompok gelar kebangsawanan, yaitu secara berurutan dari yang tertinggi: pangeran dan raden (Berg, 1902; Moedjanto, 1987).

\section{REFERENSI}

Ahimsa-Putra. Heddy Shri (2007). "Paradigma, Epistemologi dan Metode Ilmu Sosial- 
Budaya: Sebuah Pemetaan.” Makalah disampaikan dalam Pelatihan Metodologi Penelitian yang diselenggarakan oleh CRCS UGM 12 Februari-19 Maret 2007 di Yogyakarta.

Atmadja, Pangeran Adipati Aria Soeria (Tanpa Tahun). Di Tioeng Memeh Hoedjan. Tanpa Kota Terbit: Tanpa Penerbit.

Baker, Susan (2006). Sustainable Development. London: Routledge.

Berg, L.W.C. van den (1902). De Inlandsche Rangen en Titles: Java en Madoera. 'sGravenhage: Martinus Nijhoff.

Hardjasaputra, A. Sobana (2004). "Kedudukan dan Peranannya pada Abad ke-17 - Abad ke-19”. Bupati di Priangan dan Kajian Lainnya Mengenai Budaya Sunda. Bandung: Pusat Studi Sunda.

Herlina, Nina dkk. (2008). Sejarah Sumedang dari Masa ke Masa. Sumedang: Dinas Pariwisata dan Kebudayaan Pemerintah Kabupaten Sumedang.

Moedjanto, G. (1987). Konsep Kekuasaan Jawa: Penerapannya oleh Raja-raja Mataram. Yogyakarta: Kanisius.

Moertono, Soemarsaid (1985). Negara dan Usaha Bina-Negara di Jawa Masa Lampau: Studi tentang Masa Mataram II, Abad XVI sampai XIX. Jakarta: Yayasan Obor Indonesia.

Palmer, Richard E. (1980). Hermeneutics: Interpretation Theory in Schleiermacher, Dilthey, Heidegger, and Gadamer. Evanston: Northwestern University Press.

Peet, Richard \& Elaine Hartwick (2015). Theories of Development: Contentions, Arguments, Alternatives. Third edition. New York: The Gulford Press.

Redclift, Michael \& Delyse Springett (eds.) (2015). Routledge International Handbook of Sustainable Development. London: Routledge.

Schmidt, Lawrence K. (2010). Understanding Hermeneutics. Durham: Acumen Publishing.

Sumaryono, E. (1999). Hermeneutik: Sebuah Metode Filsafat. Yogyakarta: Penerbit Kanisius.
Telfer, David J. \& Richard Sharpley (2008). Tourism and Development in the Developing World. London and New York: Routledge.

Willis, Katie (2005). Theories and Practices of Development. London: Routledge.

Zed, Mestika (2008). Metode Penelitian Kepustakaan. Jakarta: Yayasan Obor Indonesia. 